\title{
Brushless DC Motor Speed Control using both PI Controller and Fuzzy PI Controller
}

\author{
Ahmed M. Ahmed \\ MSc Student at Computers and Systems Engineering \\ Department, \\ Faculty of Engineering Mansoura University, Egypt \\ Mohamed S. Elksasy \\ Assist. Prof at Computers and Systems Engineering \\ Department, \\ Faculty of Engineering Mansoura University, Egypt
}

\author{
Amr Ali-Eldin \\ Lecturer at Computers and Systems Engineering \\ Department, \\ Faculty of Engineering Mansoura University, Egypt \\ Faiz F. Areed \\ Prof at Computers and Systems Engineering \\ Department, \\ Faculty of Engineering Mansoura University, Egypt
}

\begin{abstract}
Brushless DC (BLDC) motors are one of the most interesting motors, not only because of their efficiency, and torque characteristics, but also because they have the advantages of being a direct current (DC) supplied, but eliminating the disadvantages of using Brushes. BLDC motors have a very wide range of speed, so speed control is a very important issue for it. There are a lot of parameters which need to be in focus while talking about a speed controller performance like starting current, starting torque, rise time, etc. There are two main methods for controlling the speed, PID Controllers, and Fuzzy PI controllers. Both are different in complexity and performance. In this paper, the PI and Fuzzy PI speed controllers for the BLDC motors will be proposed. A simulation study is conducted to evaluate the efficiency of the proposed speed controllers. Further, a comparative study is performed to validate the system effectiveness.
\end{abstract}

\section{Keywords}

BLDC Motor, Speed Control, PI Controller, Fuzzy Controller, Fuzzy PI.

\section{INTRODUCTION}

Automation Brushless Direct Current (BLDC) motors are used in wide fields and applications, such as Aerospace, Medical equipment, etc. This is because of its high efficiency, wide speed range and their high torque relative to motor size. Additionally, not using brushes have the following advantages[4]:

- No sparks during operation which allows using the motor in hazard areas.

- No noise from commutating sparks.

- Low maintenance cost, and long life as there is no brushes need to be replaced.

- $\quad$ Smaller motor size.

- No friction at commutator.

One of the most important advantages of these motors is the speed torque linearity, and the capability of controlling the speed by changing the applied DC voltage. BLDC motors, like any other motor, consist of a rotor and a stator. But in brushless dc motors the rotor is a permanent magnet and the stator is a winding distributed, in most cases, in three phases. BLDC motors are six steps electrically commutated, in each step, one phase is positive energized, and one is negative energized, and the third phase is floating.

This commutation can be done using Hall sensors or without using them, which is called sensorless commutation. This sensorless commutation depends on detecting the back EMF in each phase of the stator winding, and so detects the zero crossing point (ZCP) of these back EMF. When a ZCP is detected the motor shall be commutated to the next step, so a smooth continues motion can be achieved.

In $[1,2,4]$ the commutation using ZCP detection is discussed. In $[2,4,5]$ the lines voltage differences are used. In [6] the position of the rotor is detected using the differences in the phase's reactance due to their position according to the permanent magnet rotor. In [7] the rotor speed detection using back EMF and ZCP detection is discussed.

Speed control is the process of changing the electric power delivered to the motor to achieve a certain speed which is needed. Another purpose of speed control is to keep the motor speed constant with outsource disturbances in torque.

There are two main methods for controlling the speed, the Proportional integral derivative controller, and the fuzzy PI controller. In [3, 8] both conventional PI, and fuzzy PI controllers are discussed.

In case of motor speed control, using the derivative part increase the effect of noise, so the most industrial applications didn't use any derivative parts in the controllers, so in most industrial applications a PI controller is used to come over the noise issue and increase the system stability. In this paper the derivative part gain will be zero, and a PI controller will be used.

Although most industrial control systems depend on PI controllers, most of these applications are nonlinear (like temperature control), and PI tuning for nonlinear systems is very difficult [9]. On the other hand, Fuzzy PI controllers can be used for nonlinear systems, but it need good knowledge of the system for tuning.

In section 2 the conventional PI speed controller for BLDC will be discussed, and fuzzy PI speed controller will be presented in section 3. A comparative study will be presented for both PI controller, and fuzzy PI controller in section 4. Finally a comparison between PI speed controller and fuzzy PI speed controller will be shown in section5. 


\section{CONVENTIONAL PI CONTROLLER}

The target from any controller is to minimize the error between the actual output, which needed to be controlled, and the desired output, which is called the set point. In the case of speed control this error can be expressed by the following equation:

$\mathrm{e}(\mathrm{t})=\omega_{S P}(t)-\omega_{P V}(t)$

Where $\mathrm{e}(\mathrm{t})$ is the error function of time, $\omega_{S P}(t)$ is the reference speed or the speed set point as function of time, and $\omega_{P V}(t)$ is the actual motor speed as function of time. The PI term stands for Proportional Integral Derivative, so any PI controller can be divided into 3 parts each part has its Gain, the first part is the proportional part witch is the error multiplied by a constant gain which is KP. The second part is the integral part, which is the integration of error with time multiplied by a constant gain, which is KI. The third part is the derivative part, which is the derivative of error with time multiplied by a constant gain which is KD. The PI controller equation can be expressed as the following.

$\mathrm{u}(\mathrm{t})=\mathrm{K}_{P} e(t)+K_{I} \int e(t) d t$

Where $\mathrm{u}(\mathrm{t})$ is the PI output, $\mathrm{KP}$ is the proportional gain, $\mathrm{KI}$ is the integral gain, $\mathrm{KD}$ is the derivative gain, and $\mathrm{e}(\mathrm{t})$ is the error function shown in equation (1). The following function block, in figure 1, explains the operation of the PI controller.

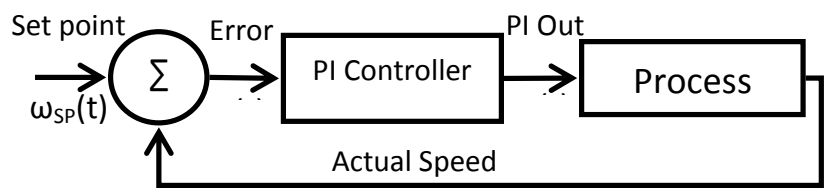

Figure 1 PI Controller Block Diagram

According to [9], there are four main parameters which should be minimized by the control system:

- Rise time (Tr): defined as the time taken to go from $10 \%$ to $90 \%$ of the targeted set point value.

- $\quad$ Settling time (Ts): defined as the time required for the response curve to reach and stay within a range of certain percentage (usually $5 \%$ or $2 \%$ ) of the final value. [10]

- Steady state error: defined as the difference between the steady state output and the desired output.

- Overshooting: defined as the maximum peak value of the response curve measured from the desired response of the system [11].Overshooting is the maximum value in the response curve minus the targeted value divided by the targeted value, and can be calculated as shown in equation 3 .

Overshooting $=\frac{\text { Max.Speed Response }- \text { Setpoint }}{\text { Setpoint }}$

There are more parameters which should be taken into account in case of motor speed control, like start up current, start up torque, and speed variation percentage.
So any controller, PI controller or fuzzy PI controller, target to reduce the rise time, settling time, steady error, and overshoot.

\section{FUZZY PI CONTROLLER}

Fuzzy controller is a logistic controller based on fuzzy logic. Fuzzy controllers depend on rules and conditions between inputs to get the output.

Fuzzy controllers rules are in terms that human can understand like tall, short, medium height, so it is easier for human to design if he has a well knowledge about the system that needed to be controlled.

The inputs of the fuzzy controller are mapped to certain values called Fuzzy sets. Any fuzzy controller consists of three parts (see Figure 2).

- Fuzzification: the process of converting the analogue input to one of the values of the fuzzy sets using a membership function.

- Rule Base: Are the logistic rules or conditions between the inputs to get the output.

- Defuzzification: is the process which convert the system output from the fuzzy sets values to analogue output value.

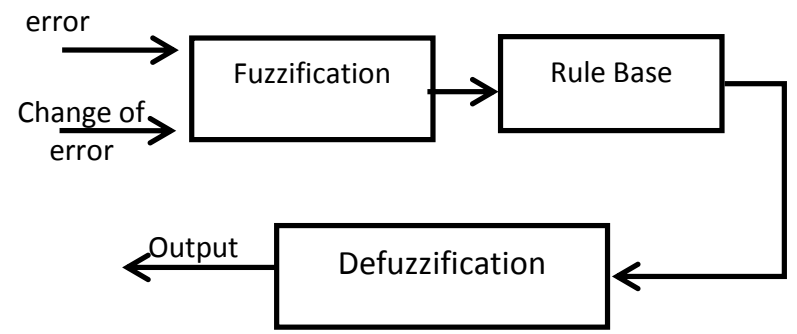

Figure 2 Fuzzy Controller Block Diagram

Most fuzzy controllers use a rectangular membership function and two fuzzy sets or more can be used. The more fuzzy sets used the more stability and better performance achieved, but also more complexity the system becomes. In case of 5 fuzzy sets, the fuzzy sets may be called Negative Big NB, Negative N, Zero Z, Positive Bid PB, and Positive P.

\section{PI CONTROLLER AND ITS SIMULATION RESULTS.}

As mentioned above most industrial applications do not use the derivative part in the PID. In this paper a PI controller is proposed. The BLDC motor parameters are shown in appendix I. The used PI coefficients are as follows: $\mathrm{KP}=0.0014$ and $\mathrm{KI}=0.17$.

At the beginning the speed is zero, and at $0.012 \mathrm{sec}$ the speed reference increases to $700 \mathrm{RPM}$, at $0.1 \mathrm{sec}$ a load of $0.1 \mathrm{NM}$ is added, and finally at $0.2 \mathrm{sec}$ the speed reference is increased to 900 RPM. Figure 3 shows the used simulation model in Simulink for the PI speed controller. 


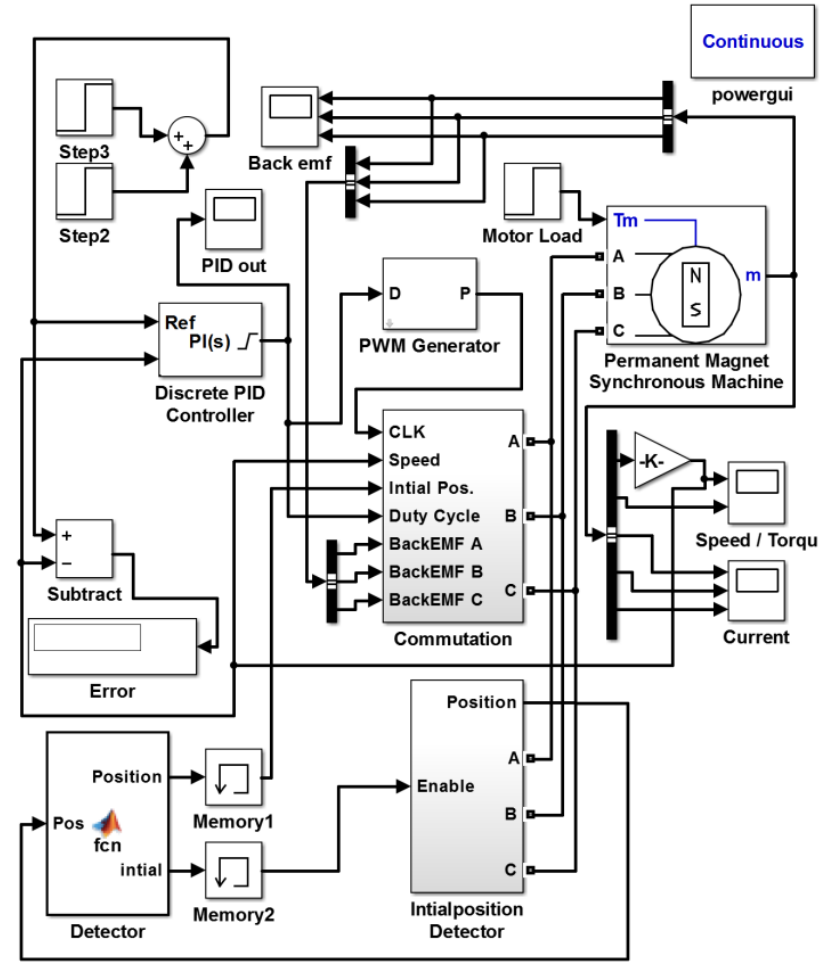

Figure 3 Used Simulink Model

In figure 4, the speed response is shown, the rise time at the first step is $0.005 \mathrm{sec}$, and there is no overshoot, the settling time is about $0.025 \mathrm{sec}$.

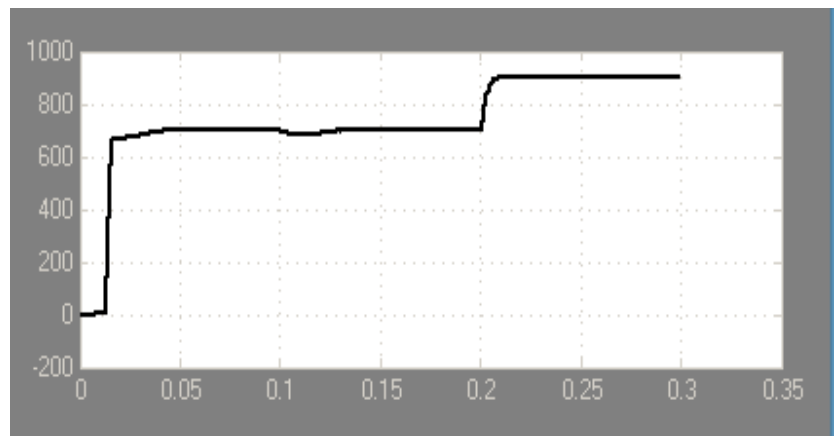

Figure 4 Speed Response using PI

For the second step (from 700 to 900 RPM), the rise time is $0.005 \mathrm{sec}$, and there is no overshoot, the settling time is about $0.0075 \mathrm{sec}$. From figure 5 , where the torque response is shown, the start-up torque is about 7.9 N.M. At $0.2 \mathrm{sec}$, where the set point changed to $900 \mathrm{RPM}$, the torque rise up to $2.2 \mathrm{~N} . \mathrm{M}$, and then returned to its steady value.

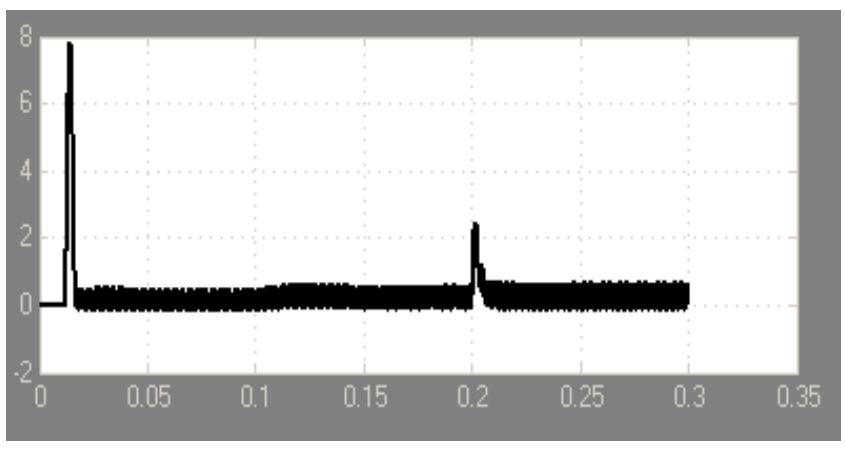

Figure 5 Torque Response using PI
In figure 6, the speed variations is less than $0.8 \%$, and at $0.1 \mathrm{sec}$ when the $0.1 \mathrm{NM}$ load is added, the speed changed to 680 RPM, and returned back to its steady value after $0.03 \mathrm{sec}$.

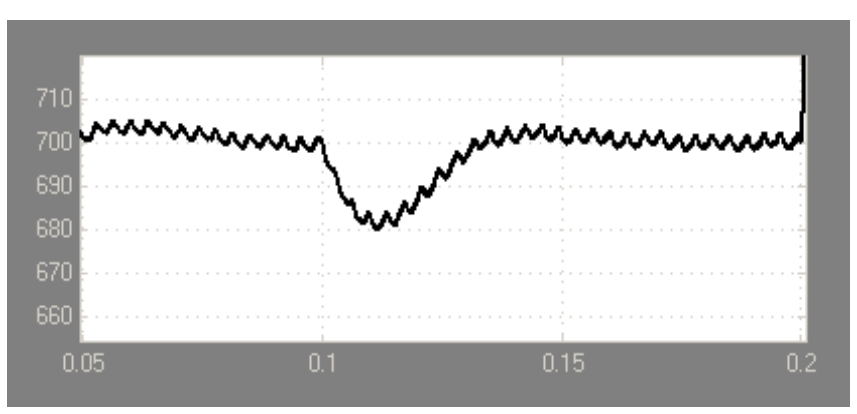

Figure 6 Speed Variations.

In figure 7, where the BLDC motor phases currents are shown, the start-up current is about $6 \mathrm{~A}$. At $0.2 \mathrm{sec}$, where the set point changed to $900 \mathrm{RPM}$, the current rise up to $2 \mathrm{~A}$, and then returned to its steady value.

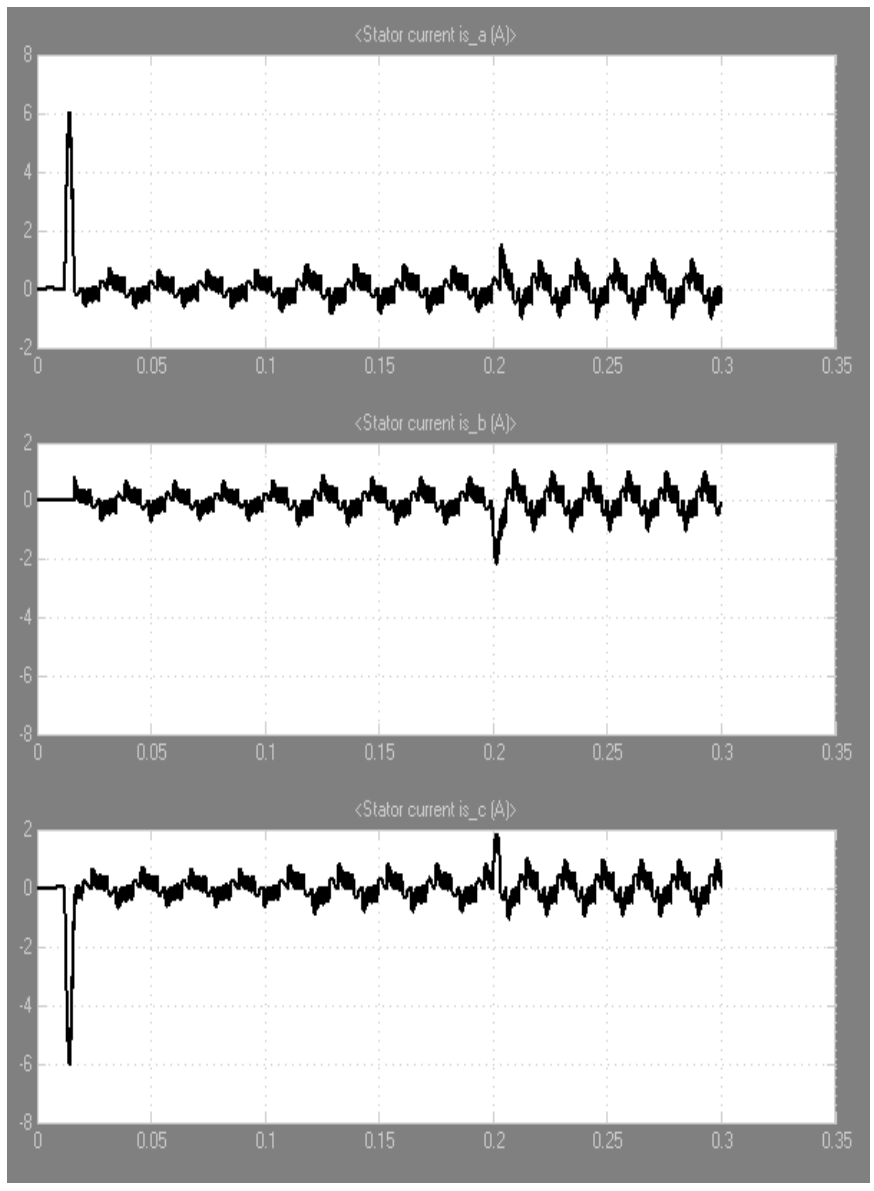

Figure 7 Stator Current in Phase a, b, and c

\section{FUZZY PI CONTROLLER AND SIMULATION RESULTS}

The proposed fuzzy PI controller use 5 fuzzy sets, NB, N, Z, $\mathrm{P}$, and $\mathrm{PB}$. And two inputs, the first input is the error, which is defined by the following equation.

$\mathrm{E}(\mathrm{N})=\omega_{S P}(N)-\omega_{P V}(N)$

Where $\mathrm{N}=1,2,3$, etc. And $\mathrm{E}(\mathrm{N})$ is the error at sample $\mathrm{N}$, $\omega_{S P}(N)$ is the reference speed or the speed set point at sample $\mathrm{N}$, and $\omega_{P V}(N)$ is the actual motor speed at sample $\mathrm{N}$. 
The second input is the change of error, which is defined by the following equations.

$$
\mathrm{CE}(\mathrm{N})=\mathrm{E}(N)-\mathrm{E}(N-1)
$$

Where $\mathrm{N}=1,2,3$, etc. And $\mathrm{CE}(\mathrm{N})$ is the change of error at sample $N, E(N)$ is the error at sample $N, E(N-1)$ is the error at sample $\mathrm{N}-1$. The membership function is a triangular function, as shown in figure 8 .

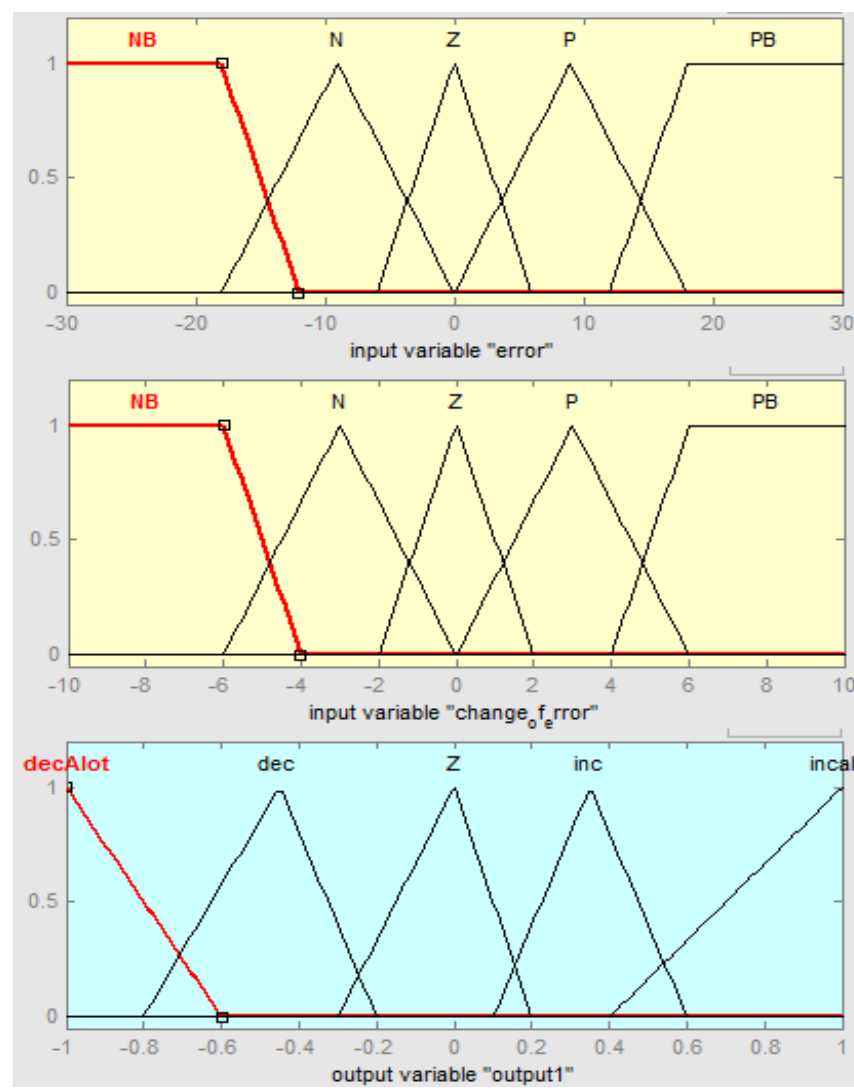

Figure 8 Fuzzy Membership Function

To optimize the fuzzy PI controller performance, a gain factor is multiplied by the error, and another one multiplied by the change of error, and another one is multiplied by the output, so the membership function range can be changed easier. These factors are 0.15 for the error, 15 for the change of error, and 0.003 for the output.

Table 1 shows the rule base of the fuzzy PI controller used, there are 25 rule used from the 5 fuzzy sets of the two inputs.

Table 1 Fuzzy PI Controller Rule Base

\begin{tabular}{|c|c|c|c|c|c|}
\hline & NB & $\mathrm{N}$ & Z & $\mathrm{P}$ & PB \\
\hline NB & NB & NB & NB & $\mathrm{N}$ & Z \\
\hline $\mathrm{N}$ & NB & NB & $\mathrm{N}$ & Z & $\mathrm{P}$ \\
\hline $\mathrm{Z}$ & NB & $\mathrm{N}$ & Z & $\mathrm{P}$ & PB \\
\hline $\mathrm{P}$ & $\mathrm{N}$ & Z & $P$ & PB & PB \\
\hline PB & Z & $\mathrm{P}$ & PB & PB & PB \\
\hline
\end{tabular}

Figure 9 shows the simulation Simulink model used for simulating the proposed Fuzzy PI controller.

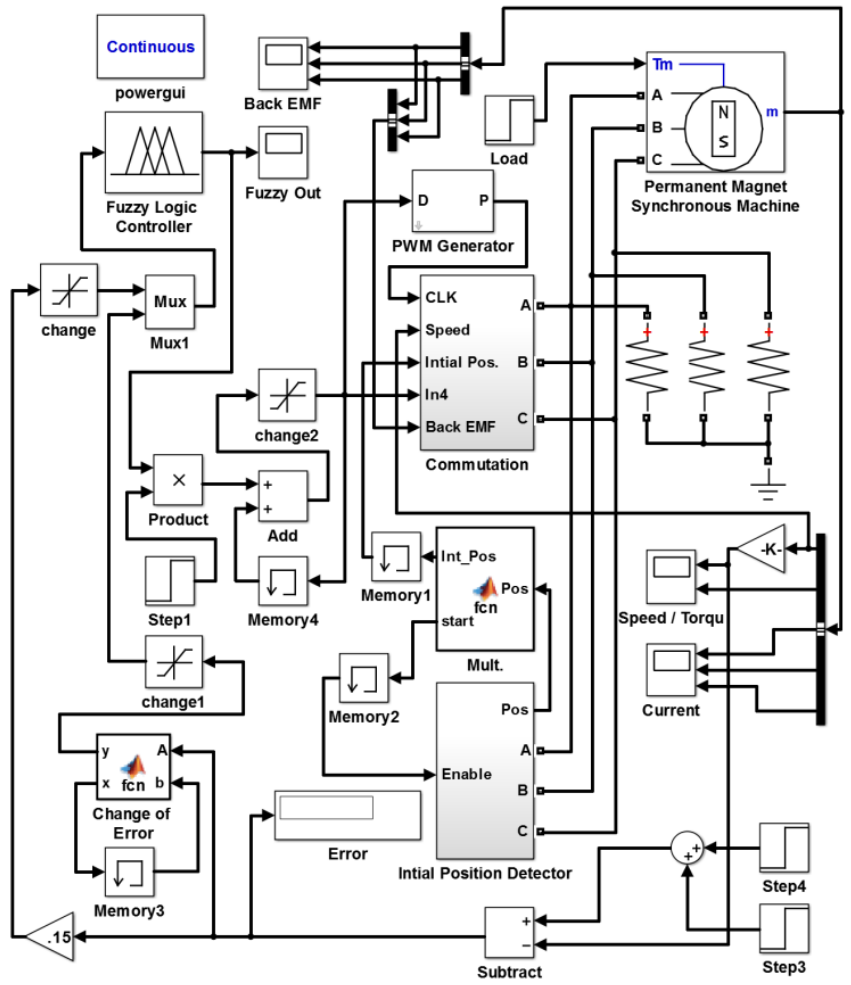

Figure 9 Fuzzy PI controller Simulink model

From figure 10, the speed response is shown, the rise time at the first step is $0.02 \mathrm{sec}$, and there is no overshoot, the settling time is about $0.023 \mathrm{sec}$. In figure 11 , the torque response is shown. The start-up torque is about 2.1 N.M. At $0.2 \mathrm{sec}$, where the set point changed to $900 \mathrm{RPM}$, the torque rise up to2.3 N.M, and then returned to its steady value.

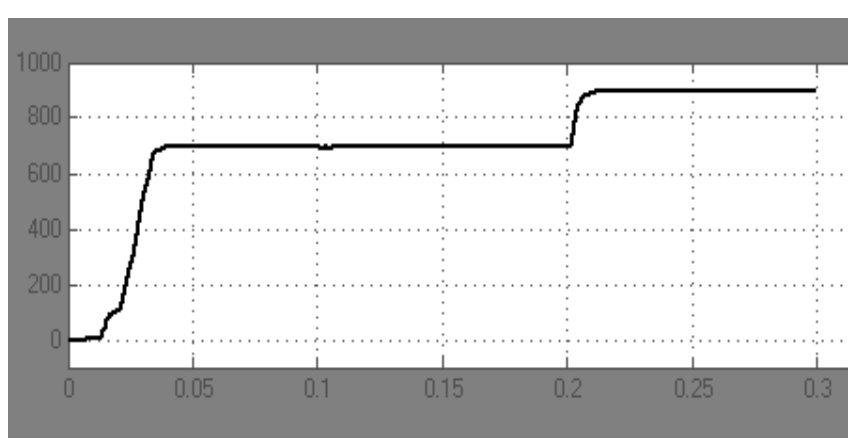

Figure 10 Speed Response using Fuzzy PI controller

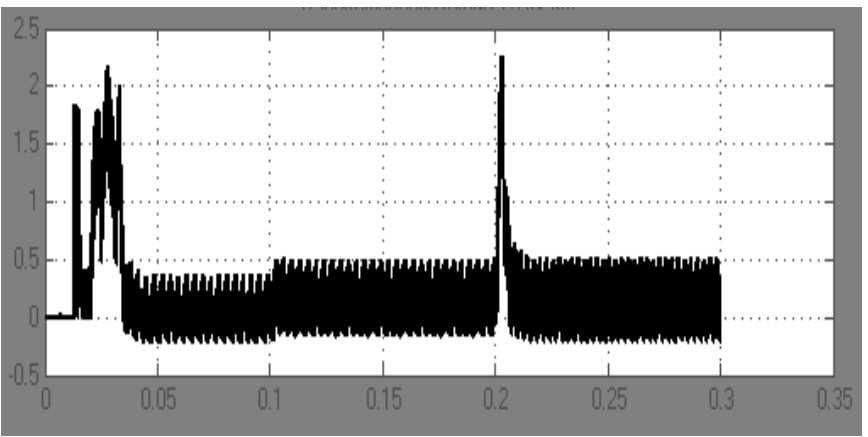

Figure 11 Torque response using Fuzzy PI Controller 
In figure 12, the speed variations is less than $0.6 \%$, and at $0.1 \mathrm{sec}$ when the $0.1 \mathrm{NM}$ load is added, the speed changed to 690RPM and returned back to its steady value after $0.01 \mathrm{sec}$.

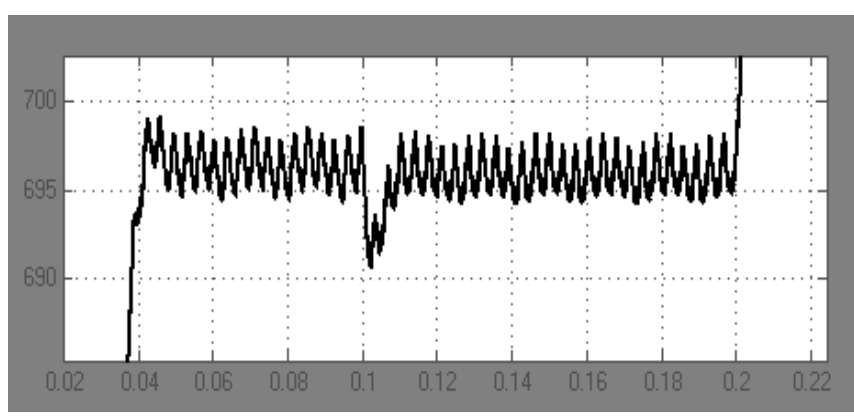

Figure 12 Speed Variations

In figure 13, where the BLDC motor phases currents are shown, the start-up current is about $2 \mathrm{~A}$. At $0.2 \mathrm{sec}$, where the set point changed to $900 \mathrm{RPM}$, the current rise up to about $2 \mathrm{~A}$, and then returned to its steady value.

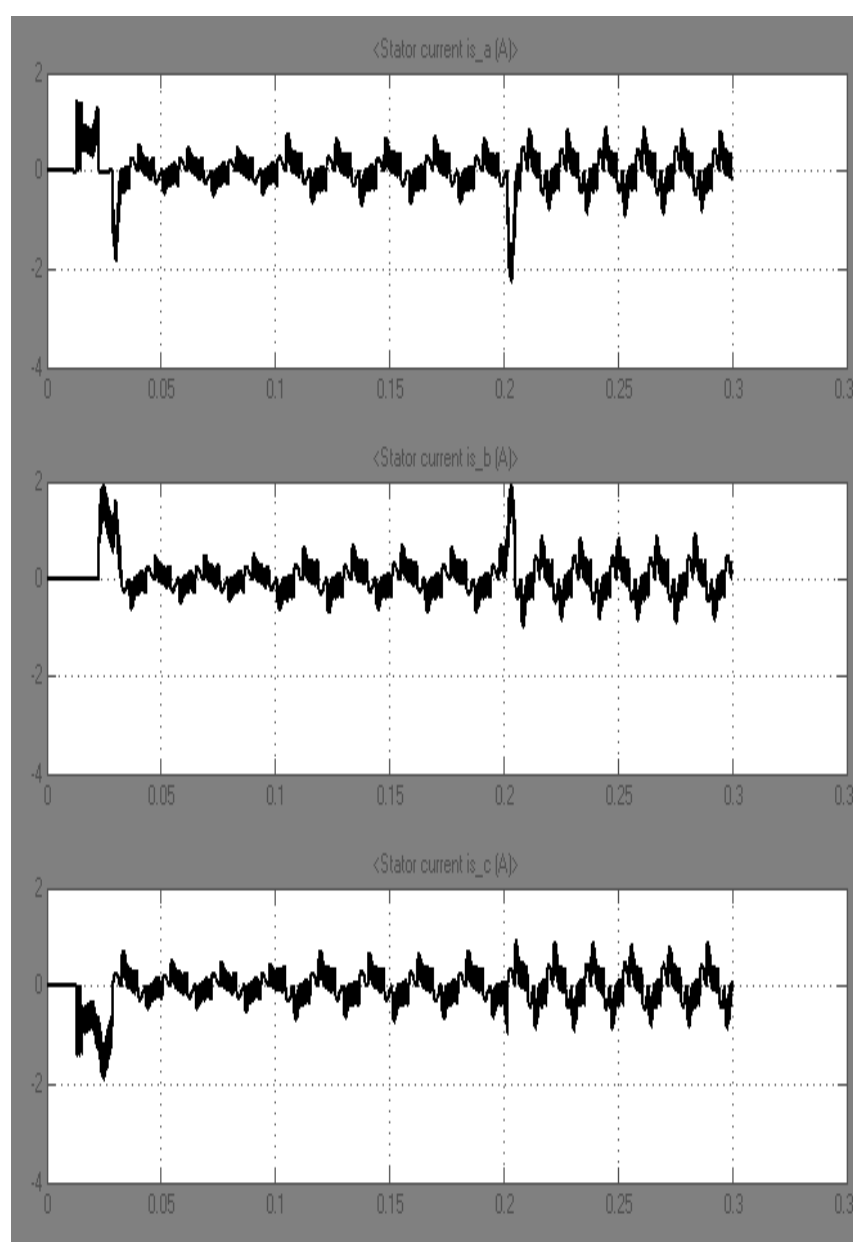

Figure 13 Motor Phases Current

\section{COMPARATIVE STUDY}

In [3] a PI speed controller and a fuzzy PI speed controller is used to control the speed of a BLDC motor with the same parameters of the one used in this paper. Table 2 shows a comparison between the performance in both papers for both the PI controller and Fuzzy PI controller.
In [3], in case of PI controller, the settling time in the first step (from 0 to 700 RPM) is $0.06455 \mathrm{sec}$. and in case of Fuzzy PI controller, the settling time is $0.05972 \mathrm{sec}$.

Table 2: Comparative Study

\begin{tabular}{|c|c|c|c|}
\hline \multicolumn{4}{|c|}{ Reference [3] } \\
\hline \multirow[t]{2}{*}{ speed } & \multicolumn{3}{|c|}{ Conventional PI Controller } \\
\hline & \multicolumn{2}{|l|}{$\operatorname{Tr}$} & Ts \\
\hline $0-700$ & \multicolumn{2}{|l|}{0.04} & 0.06455 \\
\hline $700-900$ & \multicolumn{2}{|l|}{0.005} & 0.007 \\
\hline speed & \multicolumn{3}{|c|}{ Fuzzy PI Controller } \\
\hline $0-700$ & \multicolumn{2}{|l|}{0.039} & 0.05972 \\
\hline $700-900$ & \multicolumn{2}{|l|}{0.01} & 0.018 \\
\hline \multicolumn{4}{|c|}{ Proposed Controller } \\
\hline Speed & \multicolumn{3}{|c|}{ Conventional PI Controller } \\
\hline $0-700$ & 0.005 & \multicolumn{2}{|l|}{0.025} \\
\hline $700-900$ & 0.005 & \multicolumn{2}{|l|}{0.0075} \\
\hline Speed & \multicolumn{3}{|c|}{ Fuzzy PI Controller } \\
\hline $0-700$ & 0.02 & \multicolumn{2}{|l|}{0.023} \\
\hline $700-900$ & 0.004 & \multicolumn{2}{|l|}{0.005} \\
\hline
\end{tabular}

The other performance parameters are extracted from the response speed curve of both the PI controller and the Fuzzy PI controller. From the table above, it is clear that in the first step (from 0 to $700 \mathrm{RPM}$ ), the proposed PI Controller performance is better, as the proposed one has a very small rise time, which is $0.005 \mathrm{sec}$. And it is increased in stability without oscillations.

The proposed PI controller has also a small settling time, which is $0.025 \mathrm{sec}$ with almost no overshoot. For the second step (from 700 to 900 RPM), the performance of the proposed PI controller is almost the same as the compared one, and the speed is increased in stability too.

The start-up torque in the proposed PI controller is about 7.9N.M in the first step, but in [3] the start-up torque is about 3N.M.

The start-up current in the proposed PI controller is about 6A, while in [3], the start-up current is $4 \mathrm{~A}$. so in [3], a smaller start-up current is achieved successfully, but with low start-up torque.

From the fuzzy PI controller, it is clear that in the first step (from 0 to 700 RPM), the proposed fuzzy PI Controller performance is better, as the proposed one has a very small rise time, which is $0.02 \mathrm{sec}$. and small settling time is $0.023 \mathrm{sec}$ with no overshoot. 
For the second step (from 700 to 900 RPM), the performance of the proposed fuzzy PI controller is almost better than the compared one, as the rise time is about $0.004 \mathrm{sec}$, and settling time is $0.005 \mathrm{sec}$.

The start-up torque in the proposed fuzzy PI controller is about 2.2 N.M in the first step, but in [3] the start-up torque is about 0.9781 N.M

The start-up current in the proposed fuzzy PI controller is about $2 \mathrm{~A}$, while in [3], the start-up current is $1 \mathrm{~A}$.

\section{PI CONTROLLER AND FUZZY PI CONTROLLER PERFORMANCE COMPARISON}

Table 3 contains a detailed comparison between the proposed PI controller and the proposed Fuzzy PI controller.

Table 3: Comparative Study between PI Controller and Fuzzy PI Controller.

\begin{tabular}{|c|c|c|c|}
\hline \multicolumn{2}{|l|}{ Parameter } & $\begin{array}{l}\text { PI } \\
\text { Controller }\end{array}$ & $\begin{array}{l}\text { Fuzzy PI } \\
\text { Controller }\end{array}$ \\
\hline \multirow{2}{*}{ Rise Time } & 0-700 RPM & 0.005 & 0.02 \\
\hline & 700-900 RPM & 0.005 & 0.004 \\
\hline \multirow{2}{*}{$\begin{array}{l}\text { Settling } \\
\text { time }\end{array}$} & 0-700 RPM & 0.025 & 0.023 \\
\hline & 700-900 RPM & 0.0075 & 0.005 \\
\hline \multirow{2}{*}{$\begin{array}{l}\text { Steady state } \\
\text { error }\end{array}$} & 0-700 RPM & $0 \%$ & $0.7 \%$ \\
\hline & 700-900 RPM & $0 \%$ & $0.7 \%$ \\
\hline \multirow{2}{*}{$\begin{array}{l}\text { Start-up } \\
\text { torque }\end{array}$} & 0-700 RPM & 7.9 N.M & 2.1 N.M \\
\hline & 700-900 RPM & 2.2 N.M & 2.3 N.M \\
\hline \multirow{2}{*}{$\begin{array}{l}\text { Start-up } \\
\text { Current }\end{array}$} & 0-700 RPM & $6 \mathrm{~A}$ & $2 \mathrm{~A}$ \\
\hline & 700-900 RPM & $2 \mathrm{~A}$ & $2 \mathrm{~A}$ \\
\hline $\begin{array}{l}\text { Speed } \\
\text { Variations }\end{array}$ & \multicolumn{2}{|l|}{$0.8 \%$} & $0.6 \%$ \\
\hline
\end{tabular}

\section{CONCLUSION AND FUTURE WORK}

A BLDC motor speed controller is presented in this paper, using both PI controller, and Fuzzy PI controller.

A comparative study has been done between the presented PI controller and Fuzzy PI controller, and the used references to evaluate the presented speed controllers' performance. In general the presented speed controllers have better performance. A comparison between the presented PI speed controller and the fuzzy PI speed controller has been done too, and it is clear that the performance of the fuzzy PI speed controller is in general better than the PI speed controller.

A future work could be done to add current control function to the proposed speed controller, so the current can be kept within a certain range for a given speed, which will help in enhancing the motor startup current, reducing the motor current ripples, and enhancing the motor torque characteristics. Also by current control, the speed and torque variations can be reduced to minimum, by avoiding any sudden changes in the motor current value.

\section{APPENDIX I}

The Parameters of the BLDC Motor used in this Paper.

\begin{tabular}{|l|l|}
\hline Rated speed & 3000 RPM \\
\hline Number of Poles & 4 \\
\hline Resistance/Phase (ohm) & $10.91 \mathrm{ohm}$ \\
\hline Inductance/Phase(H) & $30.01 \mathrm{e}-3 \mathrm{H}$ \\
\hline Moment of inertia(kg/m2) & $2 . \mathrm{ge}-4 \mathrm{~kg} / \mathrm{m} 2$ \\
\hline $\begin{array}{l}\text { Voltage constant } \\
\text { (V_peak L-L/ krpm) }\end{array}$ & 136.1357 \\
\hline Torque constant(Nm/A) & 1.3 \\
\hline
\end{tabular}

\section{REFERENCES}

[1] Li Chunfeng, Yu Weibo, Tang Wusheng "Study on Rotor Position of Sensorless Brushless DC Motors Through Back Electromotive Force Detection" presented at E-Product E-Service and E-Entertainment (ICEEE) 2010 International Conference on, 7-9 Nov. 2010.

[2] Xiong hui, Xue YanBo "The Design of Brushless DC Motor Back-EMF control" presented at Environmental Science and Information Application Technology (ESIAT) 2010 International Conference on, 17-18 July 2010.

[3] Madhusudan Singh , Archna Garg "Performance Evaluation of BLDC Motor with Conventional PI and Fuzzy Speed Controller " presented at 10.1109/IICPE.2012.6450516 Conference: Power Electronics (IICPE), 2012 IEEE 5th India International Conference on.

[4] Padmaraja Yedamale "Brushless DC (BLDC) Motor Fundamentals" Microchip Technology Inc, AN885 application note, 11/11/2003. Available: http://ww1.microchip.com/downloads/en/AppNotes/0088 5a.pdf.

[5] Yu-Jhen Fu, Lu-Ting Huang, Ruey-Yue Lin, and Cheng$\mathrm{Hu}$ Chen "Reliable Starting Method for Sensorless Brushless DC Motor Drive" presented at Advanced Intelligent Mechatronics (AIM) 2012 IEEE/ASME International Conference on, 11-14 July 2012.

[6] Yen-Chuan Chang and Ying-Yu Tzou "A New Sensorless Starting Method for Brushless DC Motors without Reversing Rotation" presented at Power Electronics Specialists Conference, 17-21 June 2007. PESC 2007. IEEE.

[7] M. Baszynski, and S. Pirog "A novel speed measurement method for a high-speed BLDC motor based on the signals from the rotor position sensor" IEEE, 30 January 2013 10.1109/TII.2013.2243740.

[8] Sreekala.P, and Prof.Dr.A.Sivasubramanian "Speed Control Of Brushless Dc Motor With Pi And Fuzzy Logic Controller Using Resonantpole Inverter" presented 
at Innovative Smart Grid Technologies - India (ISGT India), 2011 IEEE PES, 1-3 Dec. 2011.

[9] R. Arulmozhiyal, and R.Kandiban "An Intelligent Speed Controller for Brushless DC Motor" presented at Industrial Electronics and Applications (ICIEA), 2012 7th IEEE Conference on, 18-20 July 2012.
[10] Tay, Teng-Tiow; Iven Mareels; John B. Moore (1997). High performance control. Birkhäuser. p. 93.ISBN 0-8176-4004-5

[11] Ogata, Katsuhiko (1987). Discrete-time control systems. Prentice-Hall. p. 344. ISBN 0-13-216102-8. 